\title{
INFLUENCE OF CENTRAL CORNEAL THICKNESS (CCT) ON THE INTRAOCULAR PRESSURE (IOP) MEASUREMENTS TAKEN FROM GOLDMANN APPLANATION TONOMETER, TONOPEN, AND AIRPUFF TONOMETER.
}

\author{
Khatri $K C A^{1^{*}}$, Thapa $M^{2}$, Kharel $M^{3}$, Shah $A^{4}$, Bhattarai $K^{5}$, Joshi $K^{6}$
}

\begin{abstract}
Affiliation
1. Fellow of Vitreo-Retinal Surgery, Lumbini Eye Institute, Lumbini, Nepal

2. Lecturer, B.P.Koirala Lions Centre for Ophthalmic Studies, Institute of Medicine, Tribhuvan University, Kathmandu, Nepal

3. Resident, Department of Ophthalmology, Nepalese Army Institute of Health Sciences, Kathmandu, Nepal

4. M.D Ophthalmologist, B.P.Koirala Lions Centre for Ophthalmic Studies, Institute of Medicine, Tribhuvan University, Kathmandu, Nepal

5. Resident, B.P.Koirala Lions Centre for Ophthalmic Studies, Institute of Medicine, Tribhuvan University, Kathmandu, Nepal

6. Resident, Lumbini Eye Institute, Lumbini, Nepal
\end{abstract}

\section{ARTICLE INFO}

\section{Article History}

Received : 16 January, 2018

Accepted : 30 November, 2018

Published : 31 December, 2018

(C) Authors retain copyright and grant the journal right of first publication with the work simultaneously licensed under Creative Commons Attribution License CC - BY 4.0 that allows others to share the work with an acknowledgment of the work's authorship and initial publication in this journal.



ORA 85

DOI: $\underline{10.3126 / \text { bjhs.v3i3.22170 }}$

\section{* Corresponding Author}

Dr. Anadi Khatri (K.C.)

Fellow of Vitreo-Retinal Surgery

Lumbini Eye Institute, Lumbini, Nepal

Email:anadikc@gmail.com

ORCID: https://orcid.org/0000-0002-0444-224X

\section{Citation}

Khatri KC A, Thapa M,Kharel M, Shah A, Bhattarai K, Joshi K. Influence of Central Corneal Thickness (cct) on the Intraocular Pressure (iop) Measurements Taken from Goldmann Applanation Tonometer, Tonopen, and Airpuff Tonometer. BJHS 2018;3(3)7: 532-536.

\section{ABSTRACT}

\section{Introduction}

Intraocular pressure (IOP) is one of the basic and most important investigations. Central corneal thickness influences IOP measured by various devices.

\section{Objective}

In this study, we attempt to determine the agreement and influence of the central corneal thickness in the measurement of IOP obtained by Goldman applanation tonometer, Airpuff tonometer and tonopen.

\section{Methodology}

A cross-sectional analytical study of Central corneal thickness (CCT) was done using Ultrasonic pachymetry. IOP was adjusted using Ehler's formula. Mean and the standard deviation was measured using the observed and predicted values for each instrument for its accuracy irrespective of the CCT.

\section{Results}

200 eyes of 100 patients were included in the study. Mean IOP measured was $16 \mathrm{mmHg}$ (SD 4). Tonopen was found to have closer observed values when compared with the predicted values to IOP obtained by Goldmann's applanation tonometer after CCT adjustments with Mean difference of $0.0134 \mathrm{mmHg}$ with SD of 0.814 . Air Puff tonometer was found to be the least accurate with Mean difference $2.08 \mathrm{mmHg}$ and SD of 4.704. Linear regression analysis also predicted that while the tonopen tend to underestimate the IOP levels by $5 \%$, Airpuff tonometer had a tendency to overestimate the IOP by $13 \%$. $(p<0.05)$

\section{Conclusion}

Tonopen had the greatest agreement and significant correlation with the GAT over a range of IOP and CCT and replicate measurements that are closest to the values obtained by using GAT after CCT adjustments. CCT adjustments may not even be required or has very little influence on IOP when using Tonopen.

\section{KEYWORDS}

Airpuff, Central corneal thickness (CCT), Glaucoma, Goldmann Applanation tonometer(GAT), Intraocular pressure (IOP), Noncontact tonometer (NCT)Tonometry, tonometer, Tonopen 


\section{INTRODUCTION}

Glaucoma is a chronic and often progressive optic neuropathy with typical structural and functional changes in the optic nerve head. Intraocular pressure (IOP) remains the one and an only adjustable risk factor for glaucoma $\cdot{ }^{1-3} \mathrm{~A}$ normal IOP is necessary to maintain the integrity of the eye and its visual function. A prolonged elevation in IOP often results in irreversible damage to the retinal ganglion cells and postganglionic nerve fibers. ${ }^{4,5}$ Elevated IOP is not the cause of all damage in POAG-but a major risk factor. ${ }^{6.8}$ The issue of IOP, however, has been made controversial by corneal thickness- which is both a parameter that may cause inaccurate readings with applanation tonometry and an independent factor that may be predictive of the risk of developing open-angle glaucoma. ${ }^{9}$ The mechanism by which elevated IOP damages the optic nerve is not clear, but ischemia of the optic disc or nerve fiber layer, direct mechanical compression of axons, local toxicity, or some combination of these has been implicated.

One of its variant and the most common form-Primary open-angle glaucoma (POAG) is a chronic, progressive, anterior optic neuropathy that is associated with characteristic cupping and atrophy of the optic disc, visual field loss, open angles, and no obvious causative ocular or systemic conditions. ${ }^{10}$ POAG accounts for nearly three-quarters $(74 \%)$ of all glaucoma cases. ${ }^{11,12}$ In most cases, estimates, and Metaanalysis data show that estimated there could be 60.5 million people with Open Angle Glaucoma (OAG) and Angle Closure Glaucoma (ACG) in 2010..$^{11,13}$

The 1981 Nepal Blindness Survey estimated that there were 117,623 blind people in Nepal. Glaucoma was found to be an important cause accounting for $3.2 \%$ after cataract (66.8\%) and retinal diseases (3.3\%). Recent data collected at regional or district levels have shown that even if one is considering the lowest POAG prevalence to make a nationwide estimate, such as $3.25 \%$ for the Tharu ethnic group in our study, this would tentatively suggest 645,585 people with POAG in Nepal. It can be additionally estimated that 30,342 people could be blind in Nepal due to POAG. ${ }^{14}$

There has been a rapid development of tonometry instruments in recent years to ensure a more accurate measurement of IOP. ${ }^{15-17}$ However, confounding forces such as Central corneal thickness (CCT) cause inaccuracy in its measurement. ${ }^{18-20}$ CCT is an established independent predictor for the development of primary open-angle glaucoma (POAG) as per the Ocular Hypertension Treatment Study $(\mathrm{OHTS})^{7}$ and the European Glaucoma Prevention Study (EGPS). ${ }^{21}$ It has been postulated that the risk of POAG doubled for every $40 \mu \mathrm{m}$ decrease in CCT from the overall mean of $573.3 \mu \mathrm{m}$ from the OHTS and EGPS pooled sample. ${ }^{22}$

Goldmann and Schmidt ${ }^{23}$ hypothesized that surface tension and corneal rigidity would nullify one another and would not influence the IOP measurements if the contact that the tonometer would make to the cornea is $3.06 \mathrm{~mm}$ in diameter.
The concept of Applanation tonometry is derived from the Imbert-Fick law, It works on the principle that the force required to flatten a sphere is equal to the product of the pressure at which the sphere is inflated and the area applanated. The criteria that must be met for the above law to be applicable are- the surface is dry, flexible, thin and spherical as possible.

When we are measuring the IOP of an eye using applanation, we must keep in mind the two major forces that will influence the measurements. The surface tension of the tear film-although in microlevels - it tends to pull the tonometer head toward the cornea and increase applanation. The corneal rigidity then starts its part. It is often considered at the force required to bend the cornea- which also resists applanation.

The calculations were based on assumptions that the pressure required to flatten the cornea would be the same for all corneas. However, if a cornea is thicker than the average, it seems sensible to have to be applanted by a greater force.

GAT measurement was found to be influenced by the individual's central corneal thickness. If changes in the central corneal thickness are not considered, GAT assumes a standard of $520 \mu \mathrm{m}$ for all corneas. ${ }^{23}$ In most studies, the normal range was from 427 to $620 \mu \mathrm{m}^{24}$

Intraocular pressure (IOP) is one of the basic investigations. ${ }^{25}$ It is the only modifiable risk factor for the development and progression of $\mathrm{POAG}^{7,26}$ It has been assumed that increased IOP stresses the optic nerve head ( $\mathrm{ONH}$ ) and lamina cribrosa and its adjacent tissues ${ }^{7,26,27}$ Furthermore, IOP- inflicted impact can also compress lamina cribrosa and interfere with the axonal transport of trophic factors indispensable for the auto- regulation, and survival of retinal ganglion cells. ${ }^{28}$ Since lamina cribrosa is the location where retinal ganglion cell axons cluster before they pass through the brain, unwarranted mechanical strain can cause glaucoma damage to this structure. ${ }^{27}$

In the 1970s, Ehlers et al carried out a number of studies to evaluate the impact of CCT on IOP. ${ }^{29-31}$ From their manometric report, it was shown that the average tonometry error was $0.71 \mathrm{mmHg}$ for a $10 \mu \mathrm{m} \mathrm{CCT} \mathrm{deviation} \mathrm{of} 520 \mu \mathrm{m}$. Johnson et al reported a $900 \mu \mathrm{m} \mathrm{CCT} \mathrm{patient} \mathrm{with} 11 \mathrm{mmHg}$ manometric IOP. ${ }^{32}$ Whitacre ${ }^{33}$ illustrated an overstatement of IOP of as much as $4.9 \mathrm{mmHg}$ in thin corneas in a manometric study with the Perkins tonometer, with thick corneas producing an overestimation of as much as $6.8 \mathrm{mmHg}$. This conversed to a calculated range of 0.18 to $0.49 \mathrm{mmHg}$ IOP change for a $10-\mu \mathrm{m} \mathrm{CCT} \mathrm{change} \mathrm{from} \mathrm{the} \mathrm{mean} \mathrm{CCT.} \mathrm{This}$ showed that the relationship of CCT on IOP was not linear and IOP had to be corrected for over or underestimation using the CCT values.

Most cases of POAG are discovered through screening programs or on routine ocular examinations ${ }^{34,35}$ Measurement and recording of IOP are required not only in initiating treatment but also in monitoring the response to treatment and progression of the disease. ${ }^{36,37}$ The main objective of 
treatment is to maintain good visual function for the life of the patient and to prevent interference with the quality of life. ${ }^{38}$

Since the CCT causes such variation in the IOP measurements, in this study, we attempt to determine the influence of the central corneal thickness in the measurement of IOP obtained by Goldman applanation tonometer(GAT) (HaagStriet), noncontact Airpuff tonometer (NT-530) and handheld tonopen(Reichert Tonopen $\mathrm{XL}$ ) tonometer in patients attending general ophthalmology OPD in a tertiary eye center in Nepal and its use in a community ophthalmology setting.

\section{METHODOLOGY}

A cross-sectional analytical study in which IOP was measured in 200 eyes of 100 patients using the three tonometers. Over a 2 month, patients of both sexes between the ages of 16-80 years attending the outpatient services were randomly screened and included in this study. This study was conducted at tertiary eye care center -Birat eye Hospital in Nepal and the reporting period was from $1^{\text {st }}$ May 2018 to $1^{\text {st }}$ July 2018. The protocol was reviewed and approved by the ethics committee and adheres with the tenets of the Declaration of Helsinki.

Diagnosed cases of POAG regardless of gender along with the stage fulfilling the diagnostic criteria attending OPD were included in the study. Patients having narrow-angle in either eye or with PACG or any history of intraocular surgery (E.g.: Vitreo-retinal Procedures, Glaucoma Filtration surgeries), secondary open angle-closure glaucoma, inflammatory glaucoma, acute congestive glaucoma, corneal anomaly, scarring or abnormalities that may cause irregular surface or thickness and optic disc anomalies were excluded.

Visual Acuity was taken using standard Snellen's chart and tumbling E chart, Conjunctiva, episclera, and sclera were examined using Haag Streit 900 slit lamp to see any secondary causes/ post-trabeculectomy and other surgical scars.) Detailed fundus examination under mydriasis using eye drop Tropicamide $1 \%$ was performed with Heine Beta 200 direct ophthalmoscope, binocular indirect ophthalmoscopy with $+20 D$ lens and Haag Streit 900 slit lamp with +90D lens whenever indicated and feasible. Intraocular pressure was taken with the help of Goldmann applanation tonometer. Proparacaine hydrochloride ophthalmic solution USP, $0.5 \%$ was instilled in both eyes and after 30 seconds, gonioscopy was performed using indent able Volk 6 mirror gonioscopy. (Volk G-6 Six-Mirror Glass ). Spaeth's gonioscopic grading done. IOP was then measured using GAT, air puff tonometer, and tonopen.

Central corneal thickness (CCT) was measured using Ultrasonic pachymetry. IOP measured using GAT was considered as gold standard. Ehlers formula (over or underestimation of IOP by $0.5 \mathrm{mmHg}$ for every 10 -micrometer change in central corneal thickness taking 520 micrometers as standard where no adjustments are to be made) was used to adjust the observed IOP by various instruments. Mean and the standard deviation was measured using the observed and predicted values for each instrument.

Preformed proforma designed for this study was used to record the relevant history and clinical findings.

Data were analyzed using SPSS 20 software

\section{RESULTS}

200 eyes of 100 patients were included in the study. The study population comprised of 47 percent males with mean age of 51 years (95\% Cl 51.8-57.5, range $26-78$ years) and 53 percent females with mean age of 53.6 years $(95 \% \mathrm{Cl}$ $49.2-55.7$, range $20-80$ years). The mean age of all patients in this study was 55.2 years ( $95 \% \mathrm{Cl} 54.3-55.9$ years). The youngest patient enrolled was of 32 years and the oldest being 85 years. The mean CCT was 532.7 microns $(\mu \mathrm{m})(95 \%$ Cl 521.6-538.5) ranging between $469 \mu \mathrm{m}$ and $576 \mu \mathrm{m}$.

The mean of IOP measured by GAT, Tonopen and Airpuff Tonometer was $15.8 \mathrm{mmHg}(95 \% \mathrm{Cl} 14.5-17.2), 14.9 \mathrm{mmHg}$ (95\% Cl 13.9-14.3) and $17.97 \mathrm{mmHg}$ (95\% Cl 14.7-18.9).

Tonopen was found to have closer observed values when compared with the predicted values to IOP obtained by Goldmann's applanation tonometer after CCT adjustments with Mean difference of 0.0134 with SD of $0.814(p=0.036)$. (Figure 1 and Figure 2) .
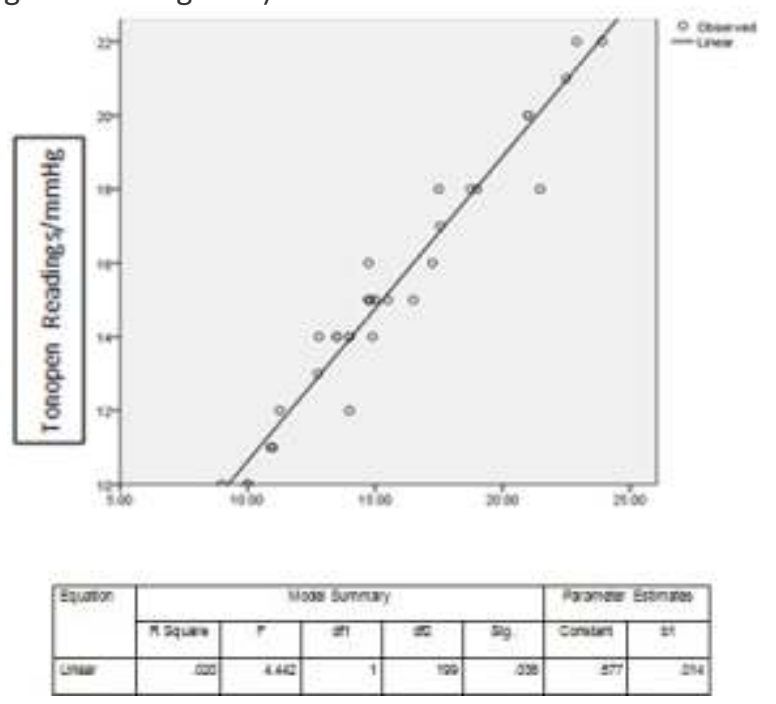

Figure 1:

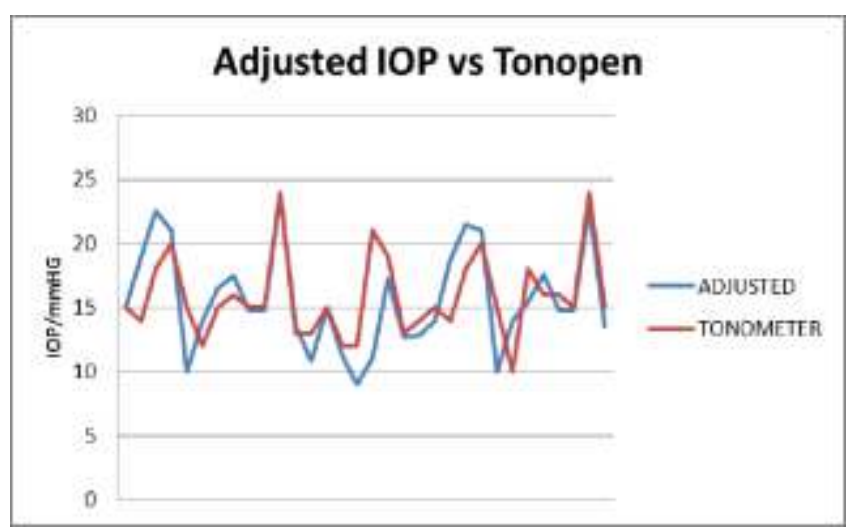

Figure 2: 
Air Puff tonometer was found to be the least accurate with Mean difference -2.08 and SD of 4.704. Linear regression analysis also showed that while the tonopen tend to underestimate the IOP levels by $5 \%$, Airpuff tonometer had a tendency to overestimate the IOP by $13 \%$ and error in measurements were significant to cause deviation from actual readings and was found to be less reliable $(p=0.159)$ (Figure 3 and Figure 4)

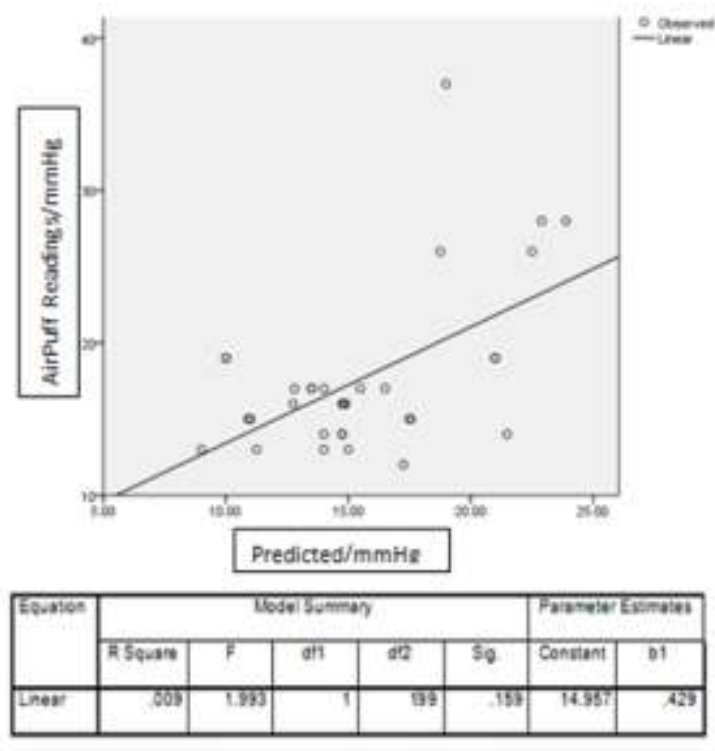

\section{Adjusted IOP vs Airpuff}

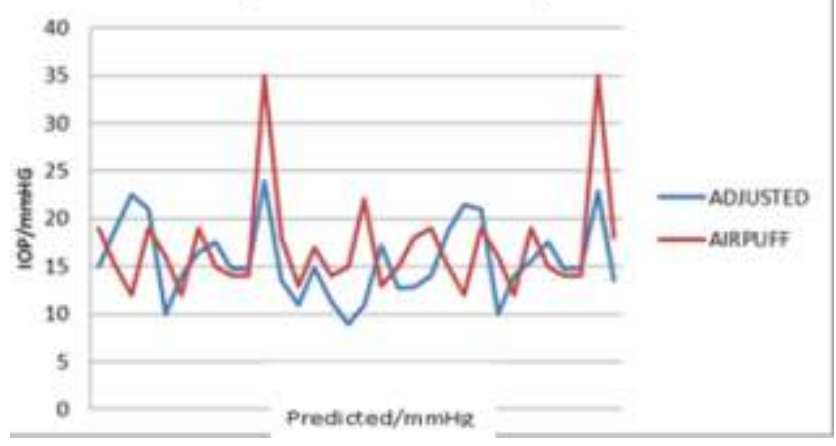

\section{DISCUSSION}

Our study was done to report the agreement of the IOP measurements obtained using different devices by comparing it with the IOP measured using GAT - which were adjusted for CCT.

The dual advantages of being portable and availability may make the tonopen tonometer a popular choice among ophthalmology trainees and optometrists in a developing country like Nepal. A good documentation of the previous IOP along with the equipment used is a must to analyze the effectiveness of treatment if the patient is receiving any for their conditions.

Tonopen had the greatest agreement and significant correlation with the GAT over a range of IOP and CCT. A study done by $A$ Bhan et al, have also reported similar finding in their study where they have concluded that the Tono-Pen was the least influenced and minimally affected by CCT when used to measure IOP in eyes with normal corneas. ${ }^{39}$ They have also reported that the pneumotonometer appears to be more affected by variation in CCT than the Goldmann tonometer. This study also shows that tonopen can be recommended and used and its measurements are closest to the values obtained by using GAT after CCT adjustments. Shields ${ }^{40}$ also concluded from his paper that NCT was less reliable in patients with elevated IOP and had a poorer correlation with GAT at higher ranges.

In another similar study done in the region by Nagarajan et al, they have also concluded from their study that the tonopens were least affected by CCT and showed accurate readings correlating with GAT readings that were adjusted with $\mathrm{CCT} .{ }^{41}$ Tonnu el $\mathrm{al}^{19}$ also had compared contact and noncontact tonometer in their study for its precision and accuracy. They also concluded that there was an appreciable inter-observer agreement with the GAT while NCT were found to be less accurate.

Tonopen is an accurate and reliable screening tool in community outreach ophthalmology services or even in tertiary eye care setup. It doesn't require any special stain and is not dependant upon the observer to match the mires for measuring the IOP.

\section{CONCLUSION}

Goldmann Tonometer remains the gold standard and the most accurate IOP measuring devices for a wide range of CCT. Airpuff although quick, is bulky equipment and its reading seems to deviate with extremes of IOP and tends to have the least accuracy among the three equipments.

\section{RECOMMENDATIONS}

Modern investigative tools like Tonopen can be recommended as a reliable diagnostic tool for glaucoma/glaucoma suspects. It can aid in keeping a track of intraocular pressure accurately.

\section{LIMITATION OF THE STUDY}

Our knowledge base is built on uncovering each piece of the puzzle, one at a time, and limitations show us where new efforts need to be made. In the end, we hope our limitation may be someone else's inspiration. A larger population group and an anterior segment Optical Coherence Tomography (OCT) or Wavefront analyzer for evaluation of the CCT would have made the findings more accurate. Since our study was performed at a tertiary center in the eastern region of Nepal, factors such as a strong regional focus, being too population-specific, or the field being only conducive to incremental findings could be an impact-limiting factor. Due to the time restriction and study being conducted in a single center, perhaps enrollment was more difficult than expected, under powering our results.

\section{ACKNOWLEDGMENT}

None.

\section{CONFLICT OF INTEREST:}

None. 


\section{REFERENCES}

1. Wangsupadilok B, Horatanaruang O.The impact of central corneal thickness on intraocular pressure measured by non-contact tonometry..J Med Assoc Thai. 2011 May;94(5):574-8.doi: 10.1111/cxo.12620.

2. Cullinane $A B$, Waldock A, Diamond JP, Sparrow JM. Optic disc cup slope and visual field indices in normal, ocular hypertensive and early glaucomatous eyes. Br J Ophthalmol. 2002;86(5):5559.PMID: 11973254.

3. Khatri A, Shrestha JK, Thapa M, Khatri BK, Kharel M. Severity of primary open-angle glaucoma in patients with hypertension and diabetes. Diabetes, Metabolic Syndrome and Obesity: Targets and Therapy. 2018;11:209-215. doi:10.2147/DMSO.S160978.

4. Quyang, P.B., Li, C.Y., Zhu, X.H., and Duan, X.C. Assessment of intraocular pressure measured by Reichert ocular response analyzer, Goldmann applanation tonometry, and dynamic contour tonometry in healthy individuals. Int J Ophthalmol. 2012; 5: 102-107.doi: 10.3980/j.issn.2222-3959.2012.01.21.

5. Sommer A, Quigley HA, Robin AL, Miller NR, Katz J, Arkell S. Evaluation of Nerve Fiber Layer Assessment. Arch Ophthalmol. 1984; 102(12) :1766-1771. doi:10.1001/archopht. 1984.01040031430017.

6. Cartwright MJ, Anderson DR: Correlation of asymmetric damage with asymmetric intraocular pressure in normal-tension glaucoma (low-tension glaucomaArch Ophthalmol. 1988;106(7):898-900. doi:10.1001/archopht.1988.01060140044020. In.

7. Gordon M, et al: The Ocular Hypertension Treatment Study: baseline factors that predict the onset of primary open-angle glaucoma, Arch Ophthalmol. 2002;120(6):714-720. doi:10.1001/archopht. 120.6.714. In.

8. Quigley HA, Addicks EM: Chronic experimental glaucoma in primates. II. Effect of extended intraocular pressure elevation on optic nerve head and axonal transport, Invest Ophthalmol Vis Sci 19:137, 1980.PMID: 6153173. In.

9. Brandt JD: Corneal thickness in glaucoma screening, diagnosis, and management, Curr Opin Ophthalmol 15:85, 2004.PMID: 15021216.

10. Stamper, R. L., Lieberman, M. F., Drake, M. V., \& Becker, B. (2009). Becker-Shaffer's diagnosis and therapy of the glaucomas. Edinburgh: Mosby/Elsevier. In p. 247.

11. Quigley HA, Broman AT. The number of people with glaucoma worldwide in 2010 and 2020. Br J Ophthalmol [Internet]. $2006 \mathrm{Mar}$ [cited 2014 Dec 20];90(3):262-7. Available from: http://www. ncbi.nlm. nih.gov/pmc/articles/PMC1856963/

12. World Health Organization. Visual impairment and blindness: Fact Sheet No 282. 2014. (accessed Sep 2014). In.

13. Tham YC, Li X, Wong TY, et al . Global prevalence of glaucoma and projections of glaucoma burden through 2040: a systematic review and meta-analysis.Ophthalmology. 2014 Nov;121(11):2081-90. doi: 10.1016/j.ophtha.2014.05.013. In.

14. Shakya-Vaidya S, Raj Aryal U, Upadhyay M, Krettek A. Do noncommunicable diseases such as hypertension and diabetes associate with primary open-angle glaucoma? Insights from a case-control study in Nepal. Glob Health Action [Internet]. 2013 Nov 4 [cited 2014 Dec 20];6(00). Available from: http://www. globalhealthaction.net/index.php/gha/article/view/22636

15. Chui, W.S., Lam, A., Chen, D., and Chiu, R. The influence of corneal properties on rebound tonometry. Ophthalmology. 2008; 115: 80-84.doi:10.1016/j.ophtha.2007.03.061.

16. Stevens S, Gilbert C, Astbury N. How to measure intraocular pressure: applanation tonometry. Community Eye Health. 2007;20(64):74-75.PMID: 18330450.

17. Farhood QK. Comparative evaluation of intraocular pressure with an air-puff tonometer versus a Goldmann applanation tonometer. Clinical Ophthalmology (Auckland, NZ). 2013;7:23-27. doi:10.2147/ OPTH.S38418.

18. Ohana O, Varssano D, Shemesh G. Comparison of intraocular pressure measurements using Goldmann tonometer, I-care pro, Tonopen $\mathrm{XL}$, and Schiotz tonometer in patients after Descemet stripping endothelial keratoplasty. Indian Journal of Ophthalmology. 2017;65(7):579-583. doi:10.4103/ijo.IJO_31_17.

19. Tonnu PA, Ho T, Sharma K, White E, Bunce C, Garway-Heath D. A comparison of four methods of tonometry: method agreement and interobserver variability. Br J Ophthalmol. 2005;89(7):847-50.doi: 10.1136/bjo.2004.056614.
20. Galgauskas S, Strupaite R, Strelkauskaite E, Asoklis R. Comparison of intraocular pressure measurements with different contact tonometers in young healthy persons. International Journal of Ophthalmology. 2016;9(1):76-80. doi:10.18240/ijo.2016.01.13.

21. European Glaucoma Prevention Study (EGPS) Group. Predictive factors for open-angle glaucoma among patients with ocular hypertension in the European Glaucoma Prevention Study. Ophthalmology. 2007;114:3-94.

22. Ocular Hypertension Treatment Study Group, European Glaucoma Prevention Study Group. Validated prediction model for the development of primary open-angle glaucoma in individuals with ocular hypertension. Ophthalmology. 2007;114:10-9.

23. Goldmann H, Schmidt T: Über Applanationstonometrie. Ophthalmologica 1957;134:221-242. doi: 10.1159/000303213.

24. Wolfs RC, Klaver CC, Vingerling JR, Grobbee DE, Hofman A, de Jong PT. Distribution of central corneal thickness and its association with intraocular pressure: The Rotterdam study. Am J Ophthalmol. 1997;123:767-72.PMID: 9535620.

25. Nucci C, Osborne NN, Bagetta G, Cerulli L, editors. Progress in Brain Research. Vol. 173. Philadelphia: Elsevier; 2008. Glaucoma: An Open Window to Neurodegeneration and Neuroprotection; p. 25.DOI: 10.1016/S0079-6123(08)01145-X

26. Heijl, A., Leske, M. C., Bengtsson, B., Hyman, L. \& Hussein, M. Reduction of intraocular pressure and glaucoma progression: results from the Early Manifest Glaucoma Trial. Arch Ophthalmol 120, 1268-1279 (2002).PMID: 12365904.

27. Remodeling of the connective tissue microarchitecture of the lamina cribrosa in early experimental glaucoma. Roberts MD, Grau V, Grimm J, Reynaud J, Bellezza AJ, Burgoyne CF, Downs JC Invest Ophthalmol Vis Sci. 2009 Feb;50(2):681-90. doi: 10.1167/iovs.08-1792.

28. Quigley, H. A. et al. Retrograde axonal transport of BDNF in retinal ganglion cells is blocked by acute IOP elevation in rats. Invest Ophthalmol Vis Sci 41, 3460-3466 (2000).PMID: 11006239.

29. Ehlers N, Hansen FK, Aasved H. Biometric correlations of corneal thickness. Acta Ophthalmol (Copenh) 1975;53:652-9.PMID: 1242286.

30. Ehlers N, Hansen FK. Central corneal thickness in low-tension glaucoma. Acta Ophthalmol (Copenh) 1974;52:740-6.PMID: 4479566.

31. Ehlers N, Bramsen T, Sperling S. Applanation tonometry and central corneal thickness. Acta Ophthalmol (Copenh) 1975;53:34-43.PMID: 1172910.

32. Johnson M, Kass MA, Moses RA, Grodzki WJ. Increased corneal thickness simulating elevated intraocular pressure. Arch Ophthalmol 1978;96:664-5.PMID: 646694.

33. Whitacre M, Stein RA, Hassanein $K$. The effect of corneal thickness on applanationtonometry.AmJ Ophthalmol.1993;115:592-6.PMID:8488910.

34. MacKean JM, Elkington AR: Alerting close relatives of patients with glaucoma, Br Med J 1:289, 1984.

35. Steinmann WC: The 'who' and 'how' of detecting glaucoma, Br Med J 285:1091, 1982.

36. Medeiros, F.A., Alencar, L.M., Sample, P.A., Zangwill, L.M., Susanna, R.Jr., and Weinreb, R.N. The relationship between intraocular pressure reduction and rates of progressive visual field loss in eyes with optic disc hemorrhage. Ophthalmology. 2010; 117: 2061-2066.doi: 10.1016/j.ophtha.2010.02.015.

37. Chan Michelle P Y, Broadway David C, Khawaja Anthony P, Yip Jennifer LY, Garway-Heath David F, Burr Jennifer M et al. Glaucoma and intraocular pressure in EPIC-Norfolk Eye Study: cross sectional study BMJ 2017; 358, doi.org/10.1136/bmj.j3889.

38. Maier PC, et al: Treatment of ocular hypertension and open angle glaucoma: meta-analysis of randomised controlled trials, BMJ 331(7509):134, 2005. Epub Jul 1, 2005. In.

39. Archana Bhan, Andrew C. Browning, Sunil Shah, Robin Hamilton, Dinesh Dave, Harminder S. Dua; Effect of Corneal Thickness on Intraocular Pressure Measurements with the Pneumotonometer, Goldmann Applanation Tonometer, and Tono-Pen. Invest. Ophthalmol. Vis. Sci. 2002;43(5):1389-1392.PMID: 11980851.

40. Shields $\mathrm{MB}$. The non-contact tonometer. Its value and limitations. Surv Ophthalmol [Internet]. 1980 Jan 1 [cited 2018 Oct 30];24(4): 211-9. Available from: https://doi.org/10.1016/0039-6257(80)90042-9

41. Nagarajan S, Velayutham V, Ezhumalai G. Comparative evaluation of applanation and indentation tonometers in a community ophthalmology setting in Southern India. Saudi J Ophthalmol [Internet]. 2016 Apr 1;30(2):83-7. Available from: http://www. sciencedirect. com/science/article/pii/S1319453415001174 